\title{
PKC signaling prevents irradiation-induced apoptosis of primary human fibroblasts
}

\author{
A Bluwstein ${ }^{1,2}, \mathrm{~N} \mathrm{Kumar}^{3}$, K Léger ${ }^{1,2}, \mathrm{~J} \mathrm{Traenkle}^{4}$, J van Oostrum ${ }^{5}, \mathrm{H}$ Rehrauer ${ }^{6}, \mathrm{M} \mathrm{Baudis}^{3}$ and MO Hottiger ${ }^{\star, 1}$
}

Primary cells respond to irradiation by activation of the DNA damage response and cell cycle arrest, which eventually leads to senescence or apoptosis. It is not clear in detail which signaling pathways or networks regulate the induction of either apoptosis or senescence. Primary human fibroblasts are able to withstand high doses of irradiation and to prevent irradiation-induced apoptosis. However, the underlying regulatory basis for this phenotype is not well understood. Here, a kinetic network analysis based on reverse phase protein arrays (RPPAs) in combination with extensive western blot and cell culture analyses was employed to decipher the cytoplasmic and nuclear signaling networks and to identify possible antiapoptotic pathways. This analysis identified activation of known DNA damage response pathways (e.g., phosphorylation of MKK3/6, p38, MK2, Hsp27, p53 and Chk1) as well as of prosurvival (e.g., MEK-ERK, CAMP response element-binding protein (CREB), protein kinase C (PKC)) and antiapoptotic markers (e.g., Bad, Bcl-2). Interestingly, PKC family members were activated early upon irradiation, suggesting a regulatory function in the ionizing radiation (IR) response of these cells. Inhibition or downregulation of PKC in primary human fibroblasts caused IR-dependent downregulation of the identified prosurvival (CREB phosphorylation) and antiapoptotic (Bad phosphorylation, Bcl-2) markers and thus lead to a proliferation stop and to apoptosis. Taken together, our analysis suggests that cytoplasmic PKC signaling conditions IR-stressed MRC-5 and IMR-90 cells to prevent irradiation-induced apoptosis. These findings contribute to the understanding of the cellular and nuclear IR response and may thus eventually improve the efficacy of radiotherapy and help overcome tumor radioresistance.

Cell Death and Disease (2013) 4, e498; doi:10.1038/cddis.2013.15; published online 14 February 2013

Subject Category: Cancer

Genotoxic stress such as ionizing radiation (IR) causes DNA damage and thereby induces diverse cellular responses such as cell cycle arrest and the activation of the DNA damage response (DDR) pathways to deal with this threat. ${ }^{1}$ These complex DDRs are regulated by the PI3K-like kinases ATM, ATR and DNA-PK, which regulate downstream effectors that induce cell cycle checkpoints via phosphorylation of checkpoint kinases (Chk1/2), phosphatases (Cdc25) as well as stabilization of p53 and activation of the p16INK4a-Rb pathway to delay progression into the $S$ phase or mitosis. ${ }^{2}$ Following the detection of DNA breaks, ATM initiates a nuclear signaling cascade, leading to the phosphorylation of protein substrates such as histone H2A.X, which is thus modified into $\gamma \mathrm{H} 2 \mathrm{~A} . \mathrm{X}$ and sensitively marks individual DNA breaks. ${ }^{3}$ Depending on the cell type, prolonged cell cycle arrest and extensive DNA damage leads to apoptosis or senescence, ${ }^{4-6}$ but the molecular mechanism leading to either of these outcomes is not understood in detail. Recent large-scale network analyses have extended our understanding not only of genotoxic stress signaling and identified new phosphorylation but also of acetylation sites and target proteins mainly in the nucleus. ${ }^{7-11}$ Reverse phase protein arrays (RPPA) represent a powerful technology for the sensitive detection and high-throughput quantification of protein changes at the single-cell level in a multiplex setting. ${ }^{12,13}$ Protein arrays have already been applied to study changed expression levels or post-translational modification status of proteins in cellular stress conditions or in normal and cancerous prostate and ovarian tissue. ${ }^{10,13-15}$

Depending on the cell type, IR induces different responses and proteome changes. MRC-5 primary human lung fibroblasts were used in this study as a model cell strain, because these cells tolerate IR doses up to $80 \mathrm{~Gy}$ and do not induce apoptosis. ${ }^{16,17}$ Here, we applied the RPPA technology to study IR-induced stress pathways in primary cells on a 'signalosome level' by analyzing cellular candidate markers. The RPPAs were probed with 165 different antibodies to quantify the major components and post-translational modifications of nuclear and cytoplasmic stress signaling events. Besides classical components of the DDR, such as protein level and phosphorylation changes in Chk1, p53, p21 and cyclin D1, as well as activation of the MEK-ERK, p38-Hsp27

\footnotetext{
${ }^{1}$ Institute of Veterinary Biochemistry and Molecular Biology (IVBMB), University of Zurich, Winterthurerstrasse 190, Zurich, Switzerland; ${ }^{2}$ Cancer Biology PhD Program, Life Science Zurich Graduate School, University of Zurich, Winterthurerstrasse 190, Zürich, Switzerland; ${ }^{3}$ Institute for Molecular Life Science (IMLS) and Swiss Institute of Bioinformatics (SIB), University of Zurich, Winterthurerstrasse 190, Zurich, Switzerland; ${ }^{4}$ Bayer Technology Services GmbH, Zeptosens Platform, Leverkusen, Germany; ${ }^{5}$ Luxembourg Clinical Proteomics Center, CRP-Santé, Strassen, Luxembourg and ${ }^{6}$ Functional Genomics Center Zurich (FGCZ), University of Zurich, Zurich, Switzerland

*Corresponding author: MO Hottiger, Institute of Veterinary Biochemistry and Molecular Biology (IVBMB), University of Zurich, Winterthurerstrasse 190, Zurich 8057 Switzerland. Tel: + 4144 6355474; Fax: + 4144 6356840; E-mail: hottiger@vetbio.uzh.ch

Keywords: apoptosis; DNA damage response; PKC signaling; primary human fibroblast; radiation sensitivity; reverse phase protein array

Abbreviations: CREB, cAMP response element-binding protein; DDR, DNA damage response; DNA, deoxyribonucleic acid; IgG, immunoglobulin G; IR, ionizing radiation; NHF, normal human fibroblast; PKC, protein kinase C; RPPA, reverse phase protein array

Received 26.09.12; revised 21.12.12; accepted 02.01.13; Edited by A Stephanou
} 
and LKB-AMPK pathways, the RPPA analysis described here also identified specific components of the cellular IR response involved in antiapoptotic and prosurvival signaling. Among these changes was also the activation of PKC family members. The PKC signaling pathway is known to integrate extracellular signals, calcium and secondary lipid messengers (diacylglycerol, phosphatidylserine), to regulate diverse cellular responses, including apoptosis or survival during genotoxic stress. ${ }^{18-20}$ We found that experimental inhibition or downregulation of PKC led to downregulation of prosurvival (cAMP response element-binding protein (CREB) phosphorylation) and antiapoptotic (Bad phosphorylation, Bcl-2) markers upon IR treatment and thus lead to apoptosis in normal human MRC5 and IMR-90 fibroblasts (normal human fibroblasts (NHFs)). These results thus implicated significantly changed kinetics of prosurvival (CREB phosphorylation) and antiapoptotic (Bad phosphorylation, Bcl-2) key determinants in the ability to prevent apoptosis upon severe DNA damage. IR-induced PKC signaling is thus defined as the mechanism that prevents IR-induced apoptosis.

\section{Results}

IR induces a DDR and senescence in MRC-5 fibroblasts. To induce DNA damage, primary human MRC-5 fibroblasts were irradiated with doses of 10 and $40 \mathrm{~Gy}$. Both doses induced key components of the classical DDR, including phosphorylation of ATM at serine 1981 (pS1981), of Chk1 at serine 345 (pS345), of H2A.X at serine 139 (pS139) and stabilization of p53 protein levels (Figure 1a). The IR doses were chosen based on preliminary experiments and reflect the high capacity to repair IR-induced DNA damage of MRC5 cells, which have been shown to efficiently remove DNA strand breaks (DSBs) up to IR doses of $80 \mathrm{~Gy}^{16}$ and to enter the senescent state upon treatment with various stress stimuli. $^{21}$ In agreement with these findings, irradiation of MRC- 5 cells with IR doses between 4 and 10 Gy induced a dose-dependent increase and time-dependent decrease of H2A.X pS139 that was mediated by ATM and DNA-PK (Figures $1 \mathrm{~b}$ and $\mathrm{c}$ ). The majority of DSBs was repaired within $8 \mathrm{~h}$ post-irradiation as indicated by the reduction of $\gamma \mathrm{H} 2 \mathrm{AX}$ foci and the remaining $\gamma \mathrm{H} 2 \mathrm{AX}$ foci continued to be repaired $24-48 \mathrm{~h}$ following IR treatment (Supplementary Figures S1a and b).

The strong reduction in colony formation of single cells after 10 days and the appearance of $\beta$-galactosidase-positive cells (MRC-5 and IMR-90) by $72 \mathrm{~h}$ after irradiation indicated growth arrest and induction of cell senescence (Supplementary Figures S1c and d), which was further supported by elevated p21 gene expression as well as p21 and p16 protein levels in MRC-5 and IMR-90 primary fibroblasts (Supplementary Figures S1e-g). Irradiation caused only a slight increase in the G2/M cell cycle population, but this effect was intensified upon ATM inhibition, suggesting that the efficient DDR prevented a more pronounced effect on cell cycle progression of irradiated MRC-5 cells (Supplementary Figures S2a-d). Cells did not exhibit elevated apoptosis even at the $8 \mathrm{~h}$ time point after $40 \mathrm{~Gy}$ irradiation, as indicated by the stable fraction of Annexin V-positive cells and undetectable expression of
NOXA, PUMA and Bax (relative to a significant increase after staurosporine or cycloheximide treatment; Supplementary Figures S3a-d).

These results documented the suitability of 10 and 40 Gy IR to induce non-lethal, but senescence responses in primary fibroblasts.

IR induces significant proteome changes in MRC-5 fibroblasts. To quantify the kinetic proteome changes upon $\mathrm{IR}, \mathrm{MRC}-5$ fibroblasts were harvested at the $0.5,2,4$ and $8 \mathrm{~h}$ time points after IR exposure (10 and $40 \mathrm{~Gy}$ ) and RPPA analysis was performed (Figure $2 \mathrm{a}$ and Supplementary Figure S4). The time points were chosen based on the observed kinetics of $\gamma \mathrm{H} 2 \mathrm{AX}$ activation (Figure $1 \mathrm{~b}$ ) and were similar to those used in earlier studies. ${ }^{7}$ The protein arrays were probed with 165 validated antibodies that specifically recognize the activation state of crucial proteins of all major signaling pathways. Only antibodies previously assessed and certified for commercial RPPA analysis services (identifying only one single band in a conventional western blot) were used and the spotted protein samples were diluted to increase the dynamic range for protein detection. ${ }^{13}$ All quantitative RPPA data of three independent biological experiments (eight technical replicates) were subjected to stringent statistical analysis (ANOVA: $P<0.05$ and fold change cutoff: fold change $\geq 1.5 \times$ S.D.) (Supplementary Figures S5-9). Altogether, 90 unique proteome changes were either significant based on ANOVA and/or passed the $1.5 \times$ S.D. cutoff (Supplementary Figures S6 and 7 and Supplementary Table).

Clustering analysis identifies early cytoplasmic signals and subsequent activation of classical DDR proteins. The analysis described here identified distinct clusters based on the temporal up- and downregulation of specific proteins or protein modifications. In general, treatment of MRC-5 fibroblasts with $40 \mathrm{~Gy}$ induced more distinct clusters as compared with $10 \mathrm{~Gy}$ irradiation and three broad groups were apparent (Figures $2 \mathrm{~b}$ and $\mathrm{c}$ and Supplementary Figures $\mathrm{S} 10 \mathrm{a}$ and $-\mathrm{b})$. The earliest changes affected many cytoplasmic proteins such as MEK1/2 (pS217/222, pS221/226), ERK1/2 (pT202/185, pY204/187), LKB (pS428) and cyclin D1 (pT286), which were sharply induced at $0.5 \mathrm{~h}$ after irradiation and relaxed to much lower and constant levels thereafter (cluster 1; Figure 2c and Supplementary Figure $\mathrm{S10b}$ ). Following this first wave of protein changes, a cluster with a distinct maximum at $2 \mathrm{~h}$ after $40 \mathrm{~Gy}$ IR appeared (clusters 2 and 5). The protein changes that appeared at later time points after 40 Gy IR comprised changes that were upregulated throughout the entire IR response or specifically increased by the higher IR dose (clusters 3 and 4). The consecutive activation and inactivation of different groups of proteins indicated a signaling cascade that progresses from the cytoplasm (early activation of MEK1/2, ERK1/2, LKB) to the nucleus (delayed activation of classical nuclear DDR proteins such as Chk1, p53, p21, MAPKAP2, Hsp27).

Validation of RPPA analysis confirms upregulation of known DDR pathways and identifies pRb downregulation. The detection of many classical DDR proteome 
a

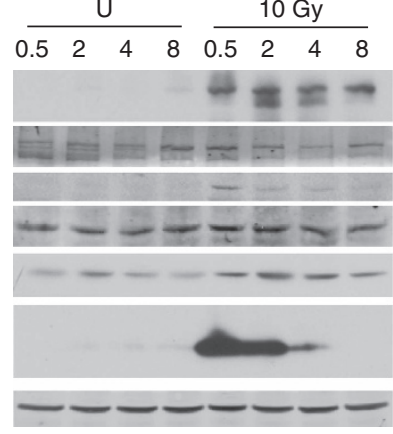

b

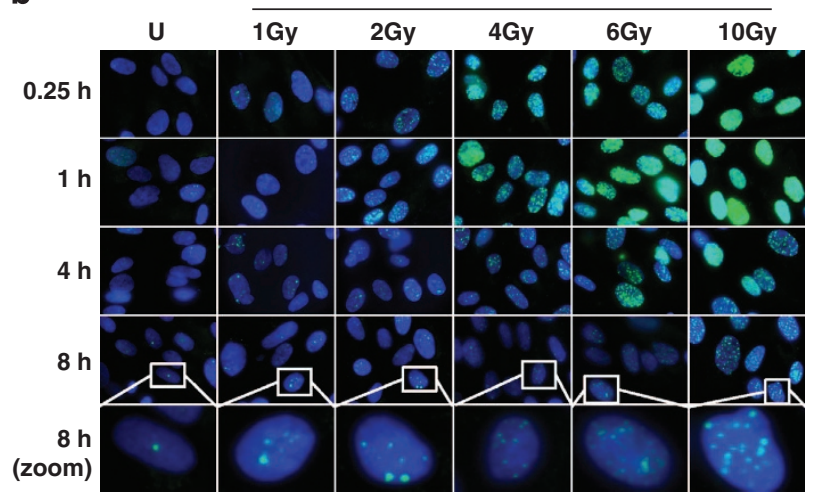

Merge: DAPI / anti- $\gamma \mathrm{H} 2 \mathrm{AX}$ (S139p)

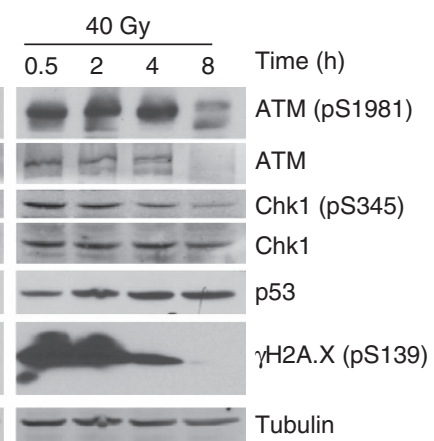

C

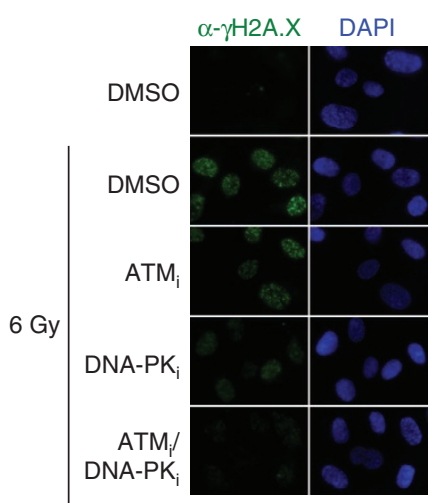

Figure 1 Induction of the DRR and efficient repair of IR-induced DNA breaks over $48 \mathrm{~h}$ in NHFs. (a) Western blot analysis of irradiated MRC-5 cells after recovery from IR for $0.5-8 \mathrm{~h}$. (b) Immunofluorescence staining of MRC-5 cells irradiated with X-ray doses of 1-10 Gy or left untreated (U) and recovered for $15 \mathrm{~min}-8 \mathrm{~h}$. (c) MRC-5 cells were pretreated with $10 \mu \mathrm{M} \mathrm{KU}-55933$ (ATMi) and/or $10 \mu \mathrm{M}$ Nu7441 (DNA-PKi) before irradiation with 6 Gy, or left untreated (U) as a control. Cells were stained with anti- $\gamma \mathrm{H} 2 \mathrm{~A}$.X (phospho-Ser139) $1 \mathrm{~h}$ post-irradiation. ATM, Ataxia-telangiectasia mutated; Chk, checkpoint kinase; DAPI, 4',6-diamidino-2-phenylindole; DNA-PK, DNA protein kinase; DMSO, dimethyl sulfoxide

changes upon both 10 and 40 Gy IR validated the RPPA analysis of IR-treated MRC-5 fibroblasts. Known proteome changes of the DDR pathway included higher total amounts of p53 and p21 as well as increased levels of phosphorylated p38 MAPK (pT180, pY182), Hsp27 (pS78), p53 (pS15) and Chk1 (pS345) (clusters 1-3 for $10 \mathrm{~Gy}$ and clusters 2-5 for $40 \mathrm{~Gy}$; Figures $2 \mathrm{~b}$ and $\mathrm{c}$ and Supplementary Figures S10a and -b). In addition, Chk1 phosphorylation upon 10 and 40 Gy IR was confirmed by western blot analysis (Figure 1a and Supplementary Figure S10c). Levels of Chk1 phosphorylation determined by RPPA and western blot analysis showed similar kinetics (early increase after 30 min recovery from IR followed by a decline over the $8 \mathrm{~h}$ time course) and thus confirmed the validity of the RPPA approach. IRinduced Chk2 phosphorylation could only be shown by western blotting because of its poor antibody performance on the arrays (Supplementary Figure S10f). Even though ANOVA $(P<0.05)$ and fold cutoff $($ S.D. $=1.5)$ analysis did not reveal significantly changed phosphorylation of the classical DDR marker H2A.X (pS139) in response to $10 \mathrm{~Gy}$, at the $2 \mathrm{~h}$ time point, the Student's $t$-test showed a significantly increased H2A.X phosphorylation $(P<0.05)$ (Supplementary Figures S7 and 8). The kinetics of H2A.X phosphorylation upon 10 and 40 Gy correlated well, but the higher dose resulted in a stronger fold induction (Supplementary Figures S8 and 9). In agreement with previously published studies, ${ }^{22}$ activation of the cytoplasmic stress kinase p38 MAPK and its downstream effector, the small heat-shock protein Hsp27, were both ATM-dependent as confirmed by western blotting and ATM inhibitor studies (Supplementary Figure S10d). Other proteome changes that were also analyzed by western blotting similarly confirmed the RPPA results, albeit western blotting revealed higher fold changes. Temporarily increased levels of p53, which is the main target for ATM in response to $I R,{ }^{2}$ correlated with delayed upregulation of p21 (clusters 1 and 2 for $10 \mathrm{~Gy}$; Figure 2b). Surprisingly, the important cell cycle regulator retinoblastoma protein $(\mathrm{pRb})$ was significantly downregulated upon 10 Gy irradiation (cluster 5; Figure 2b), representing a proteome change that has not been implicated in the IR response previously. The RPPA-based $p R b$ quantification correlated strongly with results obtained by western blotting (Supplementary Figures S10e and f), supporting in vivo $\mathrm{pRb}$ downregulation upon IR in MRC-5 fibroblasts. In contrast to total $\mathrm{pRb}$ levels, the phosphorylation of $\mathrm{pRb}$ at $\mathrm{S} 780$ (relative to total $\mathrm{pRb}$ ) increased upon $10 \mathrm{~Gy}$ after $8 \mathrm{~h}$ and already after $2 \mathrm{~h}$ following irradiation with $40 \mathrm{~Gy}$ (Supplementary Figure S10f). In line with this finding, a strong cell-cycle effect was not observed 24-48 h after irradiation compared with a clear accumulation of cells at the G1/S boundary upon hydroxyurea treatment (Supplementary Figure S2), suggesting that the $\mathrm{pRb}$ changes may be important for the maintenance of cell cycle progression during the immediate IR response. 
a

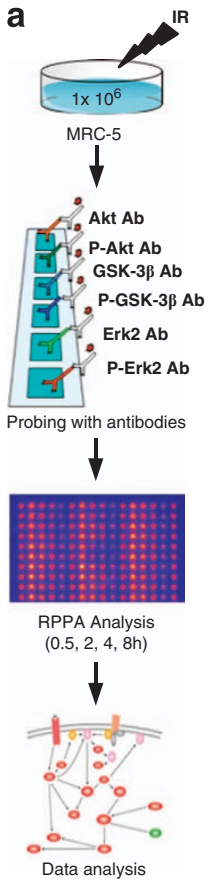

b

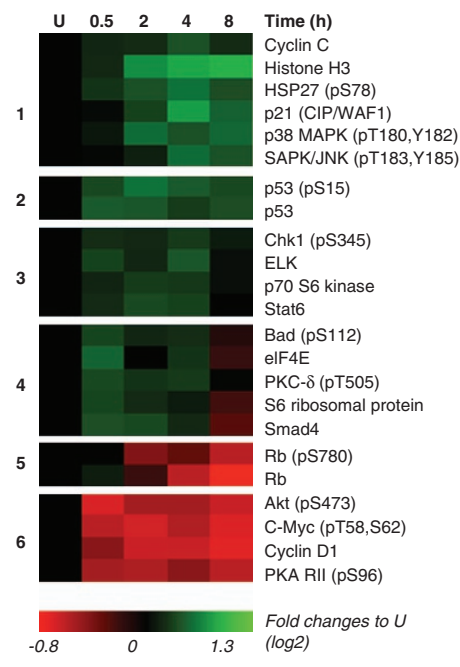

c

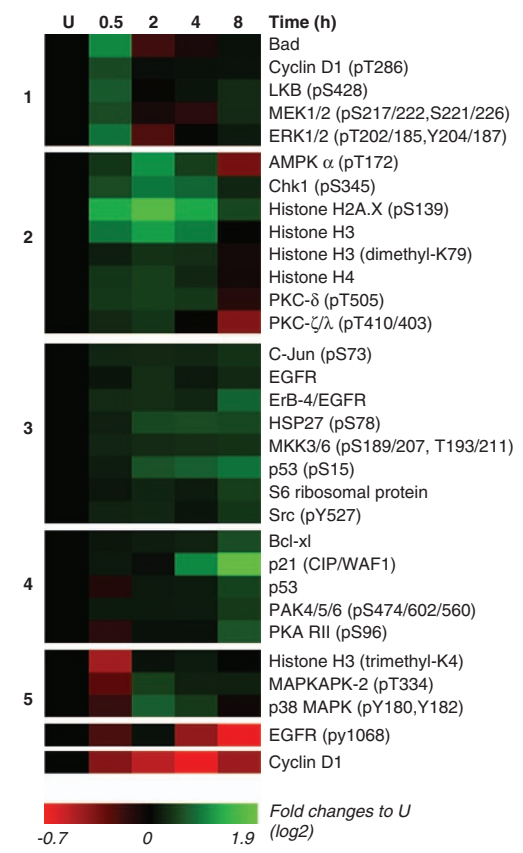

Figure 2 Identification of significant proteome changes in response to IR. (a) Workflow for the characterization of IR-induced proteome changes by RPPA. MRC-5 cells were left untreated $(\mathrm{U})$ or irradiated in biological triplicates with 10 or $40 \mathrm{~Gy}$. At different time points, cell lysates were prepared and spotted in equal amounts on hydrophobic glass slides. Each array was incubated with a different primary antibody, directed against a protein of interest and a secondary fluorophore-labeled antibody. Relative fluorescence intensities were quantified and used for statistical data analysis to identify significant proteome changes in response to irradiation. (b and $\mathbf{c}$ ) Time-profile clustering of IR-dependent proteome changes (analysis of variance (ANOVA), $P<0.05 ; 1.5$ S.D. cutoff) using Self-Organizing Tree Algorithm (SOTA) showing protein expression and modification (e.g., phosphorylation) in green or downregulation and de-modification (e.g., de-phosphorylation) in red. (b) Clustering of proteome changes upon irradiation with $10 \mathrm{~Gy}$. (c) Clustering analysis of IR-dependent proteome changes upon 40 Gy treatment. AMPK, AMP-activated protein kinase; Bad, Bcl2 antagonist of cell death; EGFR, epidermal growth factor receptor; elF4E, Eukaryotic initiation factor elF4E like protein; ERK, extracellular signal-regulated kinase; Hsp, heat-shock protein; JNK, c-Jun NH2-terminal kinase; MAPK, mitogen-activated protein kinase; MEK, MAPK/ERK kinase; PAK, p21-activated kinase; PKA RII, cAMP-dependent protein kinase type II regulatory subunit; PKC, protein kinase C; Rb, Retinoblastoma-associated protein; SAPK, stress-activated protein kinase; SMAD, Homolog of mothers against decapentaplegic homolog from Drosophila and SMA from Caenorhabditis elegans; Stat6, signal transducer and activator of transcription 6

The role of the p53 pathway in DDR and its function as a 'guardian of the genome' 23,24 is emphasized by the fact that it was significantly over-represented among the proteins responding to both 10 and 40 Gy IR (Figure 3a), and by its many interactions (more than 14 interactions) in the predicted protein network (Figure $3 \mathrm{~b}$ and Supplementary Figure S10g). The agreement of the RPPA analysis with western blot quantifications, as well as the identification of the known key players in the DDR, confirmed the validity of the RPPA approach described here and proved that the IR-treated cells used in these experiments launched a classical DDR.

\section{IR upregulates antiapoptotic and prosurvival markers in} MRC-5 cells. The kinetic RPPA analysis described here also revealed many new cytoplasmic factors, which were further analyzed in more detail. The here identified changes included prosurvival signals CREB (pS133) as well as MEK1/ 2 (pS217/222, pS221/226), ERK1/2 (pT202/185, pY204/187) and AMPK (pT172) for 40 Gy only, antiapoptotic markers (Bad pS112 and pS136, Bcl-2 pS70 for 10 Gy only) as well as a cluster comprising protein kinase C (PKC) family members. The changes in PKC family members included the phosphorylation of the novel PKC- $\delta$ (pT505) and of the atypical PKC $\zeta / \lambda$ (pT410/403) in the activation loop (Figures $2 b$ and c), which marks the activated state of these two PKC isoforms. ${ }^{25}$
These analyses suggested that IR treatment of primary fibroblasts activates not only the classical DDR pathways MEK-ERK and p38-Hsp27 but that also the cytoplasmic PKC signaling and specific antiapoptotic and prosurvival factors were regulated. It is thus possible that PKC signaling is involved in mediating the high IR resistance of MRC- 5 and IMR-90 cells by preventing apoptosis and stimulating prosurvival factors.

Inhibitor screen identifies PKC signaling as important for IR resistance. To elucidate whether PKC or other main signaling cascades regulate cell viability in NHFs upon IR treatment, a radiosensitivity screen with inhibitors specific for key components of the MEK-ERK, p38, JNK or PKC pathways was performed (Figure 4 and Supplementary Figures S11a-e). While JNK inhibitors had only a weak effect on cell viability, inhibition of MEK and p38 affected cell proliferation, but independent of IR (i.e., similar effect in treated and untreated cells). Interestingly, already $48 \mathrm{~h}$ after the cotreatment with either one of two PKC inhibitors (GF109203X or Ro-318220) and with IR, MRC-5 cells showed a significant reduction in cell viability compared with cells treated with DMSO (the solvent) or with IR alone (Figure 4 and Supplementary Figure S11). The NHF strain IMR-90 behaved similarly and showed a significant reduction 

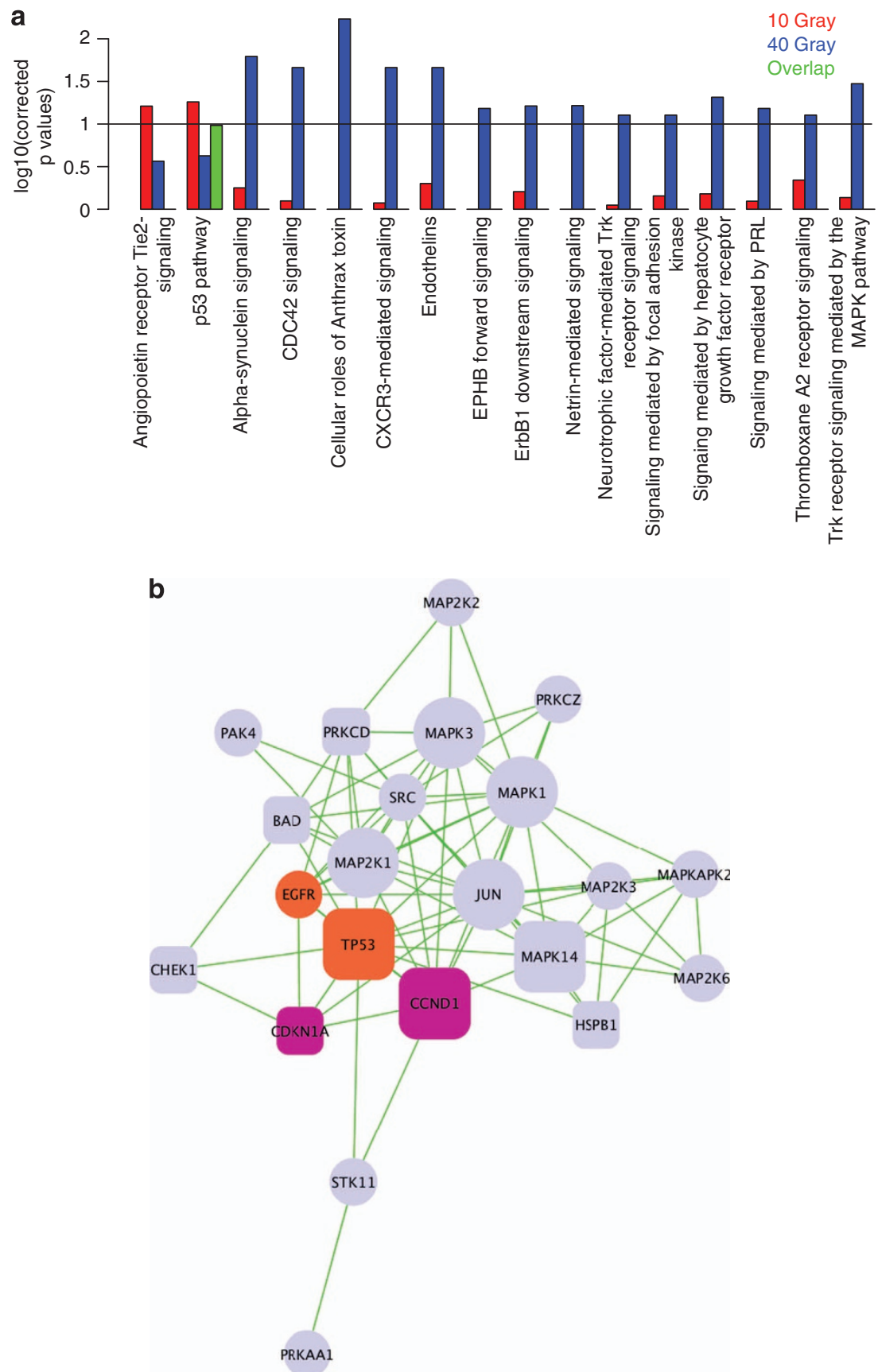

Figure 3 Pathway and protein-protein interaction analysis of significant IR-induced proteome changes. (a) Enrichment of pathways from the pathway interaction database (PID) with significant proteome changes (analysis of variance (ANOVA), $P<0.05 ; 1.5$ S.D.) induced by 10 Gy only (red), 40 Gy only (blue) and overlapping changes (green) using Fisher's exact test. (FDR-corrected $P$-value cutoff $=0.1$ ). (b) Protein-protein interaction analysis of significant proteome changes induced by 40 Gy using STRING, with a STRING score cutoff $>0.7$. Colors indicate phosphorylation (light blue), total protein changes (violet), phosphorylation and total protein changes (orange). Circles represent unique changes and squares overlapping changes. Large symbols indicate proteins that interact with more than 14 members. BAD, Bcl2 antagonist of cell death; CCND, Cyclin D; CDC42, Cell division control protein 42 homolog; CDKN1A, Cyclin-dependent kinase inhibitor 1A (p21); CHEK1, Checkpoint kinase-1; CXCR3, C-X-C chemokine receptor type 3; EGFR, Epidermal growth factor receptor; EPHB, Ephrin type-B receptor; ErbB, Epidermal growth factor receptor; HSPB, Heat shock protein beta; MAP2K1, Dual specificity mitogen-activated protein kinase kinase 1 (MEK1); MAP2K2, Dual specificity mitogen-activated protein kinase kinase 2 (MEK2); MAP2K3, Dual specificity mitogen-activated protein kinase kinase 3 (MKK3); MAP2K6, Dual specificity mitogen-activated protein kinase kinase 6 (MKK6); MAPK, mitogen-activated protein kinase; MAPK1, Mitogen-activated protein kinase 1 (ERK-2); MAPK3, Mitogen-activated protein kinase 3 (ERK-1); MAPKAP2, MAP kinase-activated protein kinase 2 (MK2); PAK, p21-activated kinase; PRKAA1, 5'-AMP-activated protein kinase catalytic subunit alpha-1 (AMPK1); PRKCD, protien kinase C delta type; PRKCZ, Protein kinase C zeta type; PRL, prolactin; SRC, Proto-oncogene tyrosine-protein kinase Src; STK11, Serine/threonine-protein kinase STK11 (LKB1); Trk, tropomyosin-receptor-kinase. 

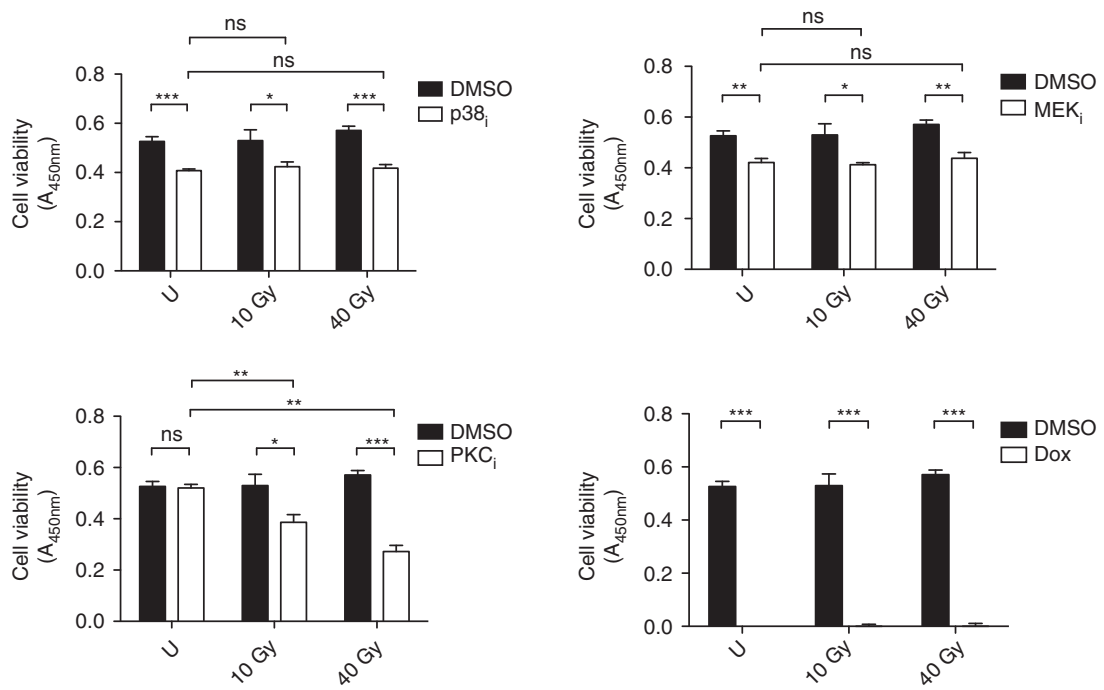

Figure 4 PKC inhibition sensitizes MRC-5 to 10 and 40 Gy after $48 \mathrm{~h}$. Cell viability assay (WST-1) of MRC-5, pretreated with p38 (SB203580, $10 \mu \mathrm{M}$ ), MEK (PD98059, $20 \mu \mathrm{M}$ ) or PKC inhibitor (GF109203X, $10 \mu \mathrm{M}$ ) and as a positive control for cell death with doxorubicin (Dox, $1 \mu \mathrm{g} / \mathrm{ml}$ ) for $2 \mathrm{~h}$ before IR and recovery for the indicated time points $(n=3)$. DMSO, dimethyl sulfoxide; MEK, mitogen-activated protein kinase/extracellular signal-regulated kinase kinase; NS, nonsignificant; PKC, protein kinase C; U, untreated; ${ }^{*} p<0.05 ;{ }^{* *} p<0.01 ;{ }^{* * *} p<0.001$

in growth when treated with the PKC inhibitor GF109203X $(2.5 \mu \mathrm{M})$ and either 10 or $40 \mathrm{~Gy}$ irradiation (Supplementary Figures S12a-c). These results implicated PKC activity and signaling in the radiosensitivity of MRC-5 and IMR-90 cells.

Inhibition or downregulation of PKC directs cells towards apoptosis. To confirm and validate PKC activation upon IR, western blot analyses were performed. In agreement with the RPPA results and the inhibitor studies, phosphorylation of $\mathrm{PKC} \zeta / \lambda$ (pT410/pT403) as well as of $\operatorname{PKC} \beta$ (pT641) were confirmed to be increased upon IR (Figures $5 a$ and $b$ ). To further characterize the mechanism of the PKC-dependent reduction in cell viability, one prosurvival (CREB phosphorylation) ${ }^{26}$ and one antiapoptotic marker (phosphorylation of Bad) $^{27}$ was analyzed in more detail by western blotting (Figures $5 \mathrm{c}-\mathrm{e}$ ). In combination with IR treatment, PKC inhibition or downregulation caused strongly reduced phosphorylation of CREB (pS133) and Bad (pS136), while the total protein levels were only marginally affected (Figures 5c and d for MRC-5; Figure 5e for IMR-90). Interestingly, ATM (pS1981) was not affected by PKC inhibition (Figures $5 c$ and e) and did not affect CREB phosphorylation or protein levels (Figure $5 \mathrm{c}$ ), suggesting that the PKC pathway is activated independent of the classical DDR.

Although primary human fibroblasts are known to undergo senescence as a response to irradiation, the reduced phosphorylation of CREB and Bad, as well as the reduced cell viability, upon IR treatment and PKC inhibition or downregulation indicated the induction of apoptosis. ${ }^{28,29}$ It was therefore assessed whether irradiation and PKC inhibition affects senescence and possibly induces apoptosis. Upon PKC inhibition and irradiation with 10 or 40 Gy, MRC-5 and IMR-90 cells both showed reduced $\beta$-galactosidase staining as compared with the DMSO-treated control, which is indicative of reduced senescence (Figure $5 f$ and Supplementary Figure S13a). Using an alternative senescence marker, reduced p16 protein levels upon irradiation, in combination with PKC inhibition or downregulation, could be confirmed in MRC-5 cells (Figure 5h). The p16 levels were not significantly reduced in IMR-90 cells in response to IR and PKC inhibition; however; the significant reduction in p21 protein levels (Supplementary Figures S13b and c) was another alternative indicator for cellular senescence. ${ }^{30}$ In contrast, in the presence of PKC inhibitors, IR treatment led to induced levels of the proapoptotic marker Bad and reduced amounts of the antiapoptotic marker $\mathrm{Bcl}-2$, persistently increased p53 protein levels (in addition to the temporary p53 stabilization observed as a response to IR alone) and ARTD1 (PARP-1) cleavage (reduction in ARTD1 full-length levels and accumulation of the $89 \mathrm{kDa}$ cleavage fragment), all suggestive of a switch from senescence to apoptosis, specifically upon IR in combination with PKC inhibitor treatment or PKC knockdown after $48 \mathrm{~h}$ of IR recovery (Figures $5 \mathrm{~g}$ and $\mathrm{h}$ ). Reduced ARTD1 levels and an increased sub-G1 cell population in the NHF strain IMR-90 also confirmed the findings with the MRC-5 strain (Supplementary Figures S13bf), in addition to the reduced senescence and cell viability upon IR treatment in combination with PKC inhibition.

In summary, these results demonstrated the IR-dependent activation of cytoplasmic PKC signaling and discovered the consecutive PKC-dependent activation of prosurvival signaling mediated via CREB and $\mathrm{Bcl}-2$ as well as the inactivation of proapoptotic pathways (Bad), which direct normal human MRC-5 and IMR-90 fibroblasts towards senescence and prevent IR-induced apoptosis (Figure 6). Activation of cytoplasmic PKC signaling upon IR is thus a novel mechanism that orchestrates the different IR-induced responses to ensure cell survival of primary human fibroblasts.

\section{Discussion}

Human primary fibroblasts such as MRC-5 cells are able to repair DNA damage induced by IR doses up to $80 \mathrm{~Gy} .{ }^{16,17}$ However, it was so far not clear how MRC-5 fibroblasts prevent 

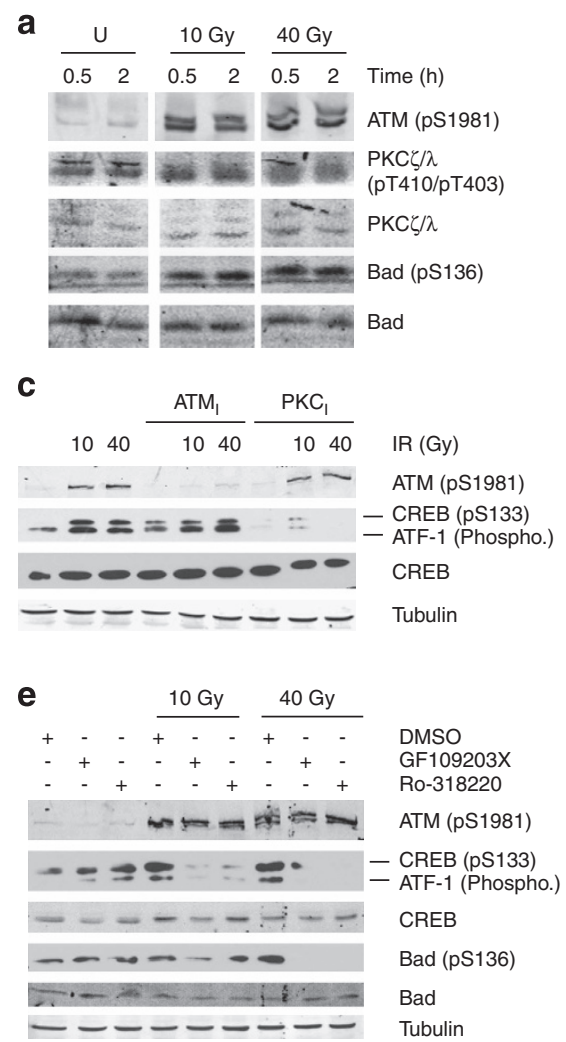

g

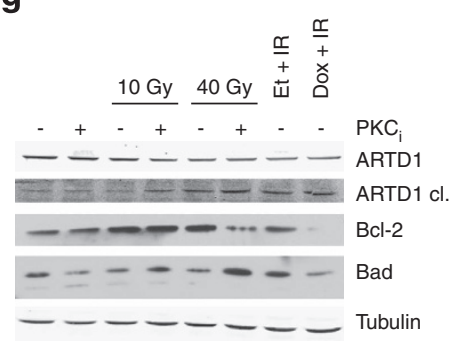

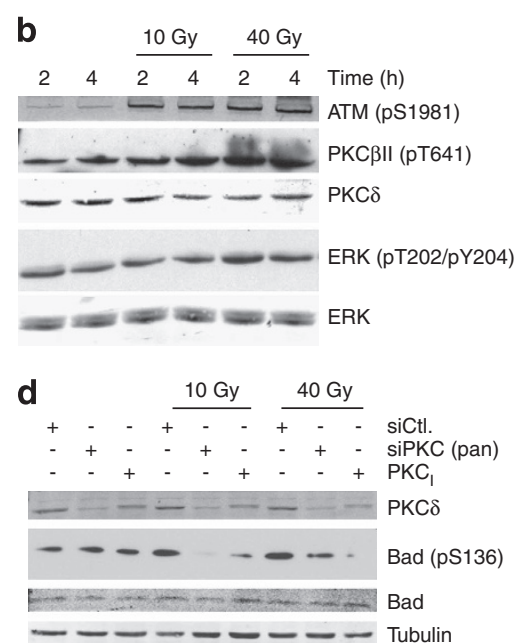

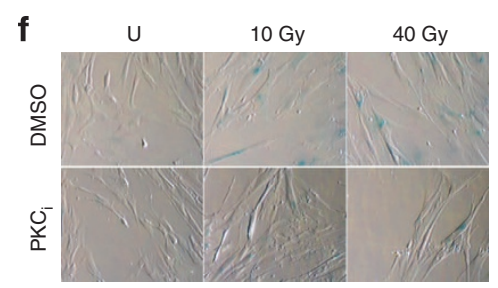

h

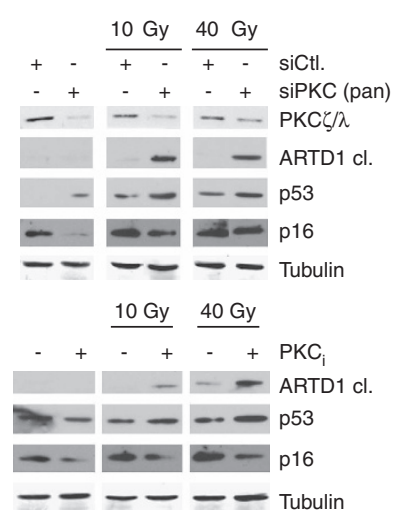

Figure 5 Inhibition or downregulation of PKC reduces prosurvival signaling in NHFs. Phosphorylation of PKC $\zeta / \lambda$ and Bad (a) or PKC $\beta \|$ and ERK (b) in response to IR. Western blot analysis of irradiated MRC-5 cells after recovery for $0.5-2$ or $2-4 \mathrm{~h}$ following IR. Total PKC $\zeta / \lambda$ and Bad (a) or total PKC $\delta$ and ERK (b) were used as loading control. (c) Phosphorylation of CREB and ATF-1 is downstream of PKC activation in response to IR. Western blot analysis of irradiated MRC-5 cells ( $4 \mathrm{~h}$ recovery) that were treated either with the PKC-specific inhibitor Ro-318220 (5 $\mu \mathrm{M}$, added before irradiation) or with the ATM inhibitor KU-55933 (10 $\mu \mathrm{M}$, added before irradiation). Tubulin was used as loading control. (d) Phosphorylation of Bad is downstream of PKC activation in response to IR. Western blot analysis of irradiated MRC-5 cells ( $4 \mathrm{~h}$ recovery) that were exposed to the PKC-specific inhibitor GF109203X ( $5 \mu \mathrm{M}$, for $2 \mathrm{~h}$ ) or siPKC pan. (e) Phosphorylation of CREB, ATF-1 and Bad is downstream of PKC activation in response to IR. Western blot analysis of irradiated IMR-90 cells ( $4 \mathrm{~h}$ recovery) that were treated with GF109203X or Ro-318220 (2.5 $\mu \mathrm{M}, 2 \mathrm{~h}$ pre-incubation before irradiation). Tubulin was used as loading control. (f) Pharmacological inhibition of PKC reduces senescence associated $\beta$-galactosidase ( $\beta$-gal) staining. SA- $\beta$-gal staining of irradiated MRC- 5 in presence of PKC inhibitor (GF109203X, $5 \mu \mathrm{M}, 72 \mathrm{~h}$ recovery) with untreated (U) as control. (g) Pharmacological inhibition of PKC (GF109203X, $5 \mu \mathrm{M}$ ) leads to ARTD1 cleavage, Bcl-2 downregulation and Bad upregulation $48 \mathrm{~h}$ after IR. (h) Knockdown of PKC leads to increased p53 stabilization and reduced p16 protein levels as well as increased ARTD1 cleavage in response to 10 and $40 \mathrm{~Gy}$ at $48 \mathrm{~h}$ after IR. Western blot analysis of irradiated MRC-5, transfected either with siPKC pan or scrambled siRNA as control for 3 days before IR. Tubulin was used as loading control. ARTD1, ADPribosyltransferase diphtheria toxin-like 1; ATF, cyclic AMP-dependent transcription factor 1; ATM, ataxia-telangiectasia mutated; Bad, Bcl2 antagonist of cell death; Bcl-2, B-cell lymphoma 2; CREB, CAMP response element-binding protein; DMSO, dimethyl sulfoxide; ERK, extracellular signal-regulated kinase; Et, etoposide; PKC, protein kinase C

apoptosis, which is induced at much lower IR doses in other cell types. ${ }^{31}$ Understanding the dynamics of in vivo signaling events in response to IR in human primary fibroblast may thus reveal medically relevant IR resistance mechanisms.

The network analysis of IR-induced proteome changes in MRC-5 fibroblasts presented here identified upregulation of known DDR factors (H2AX, p53, p21, MKK3/6, p38, MK2, Hsp27, Chk2) only 2-8h after irradiation (Supplementary
Table). In contrast, growth factor- and cytokine-dependent signaling pathways including members of the MAPK family (MEK/ERK), PKC family (PKC $\delta, \operatorname{PKC} \zeta / \lambda, \operatorname{PKC} \beta$ II) as well as anti- and proapoptotic Bcl-2 family members (Bcl-2, Bad) tended to respond with faster kinetics and thus indicated that cytoplasmic signaling events are upstream of the canonical DDR. Indeed, an increasing body of evidence implicates an IR-dependent cytoplasmic signaling network in regulating 

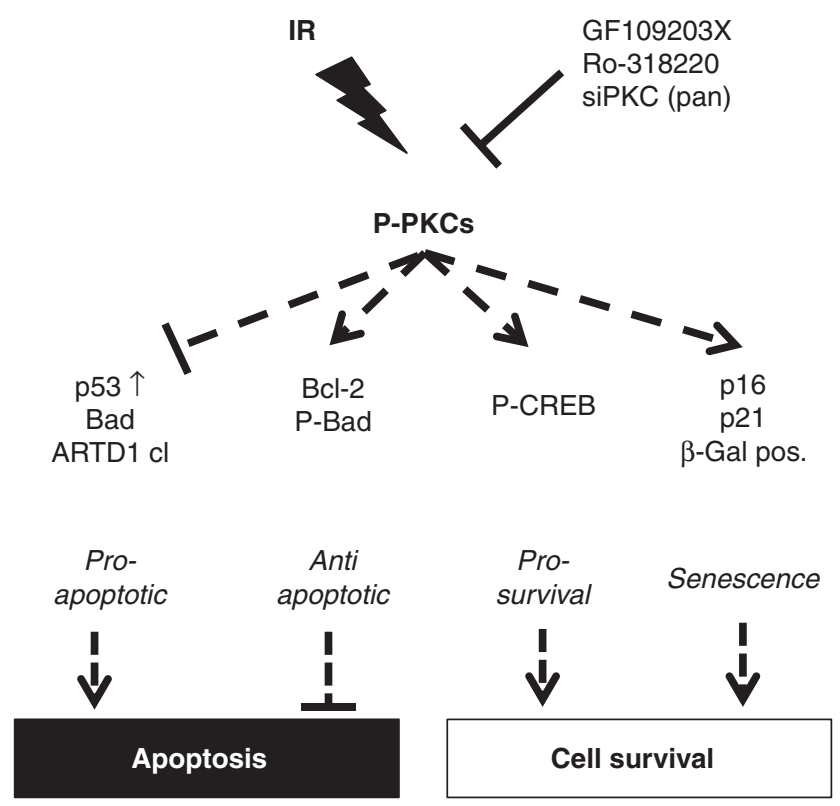

Figure 6 Model of PKC-dependent cellular prosurvival signaling in response to IR. IR-induced PKC signaling orchestrates cell survival via upregulation of $\mathrm{Bcl}-2$ and phosphorylation of Bad and CREB. Hypersensitization with PKC inhibitors (GF109203X, Ro-318220) and genetic knock down (siPKC pan) leads to IRinduced activation of apoptosis mediated by $\mathrm{p} 53$ stabilization, upregulation of $\mathrm{Bad}$ and ARTD1 cleavage, as well as reduced senescence mediated via decrease in p21 protein levels and reduced $\beta$-galactosidase ( $\beta$-Gal) activity in response to IR. ARTD1, ADP-ribosyltransferase diphtheria toxin-like 1; Bad, Bcl2 antagonist of cell death; Bcl-2, B-cell lymphoma 2; CREB, cAMP response element-binding protein

DNA break repair. ${ }^{32}$ Although RPPA analysis is restricted by antibody performance and reduced dynamic range, western blotting confirmed the tested proteome changes discovered by RPPA analysis, supporting the stringent statistical analysis. However, western blotting indicated that RPPA analysis usually underestimated the IR-induced proteome changes.

Most proteome changes, in particular upon $40 \mathrm{~Gy} \mathrm{IR,}$ affected mitogenic signaling events controlling cell survival (MKK3/6-p38-MK2 pathway, MEK-ERK pathway, LKB-AMPK pathway, PKC-Bad pathway). Previously published results have demonstrated p38-MK2 pathway activation and subsequent cell cycle arrest in G2/M in response to UV irradiation, thus protecting DNA damaged cell from entering mitosis, which would lead to a mitotic catastrophe and eventually to apoptosis. ${ }^{33,34}$ In agreement with these findings, in response to 10 and even more pronounced upon $40 \mathrm{~Gy}$, we could show activation of the major p38-MK2 pathway components, with phosphorylation of MKK3/6, p38, MAPKAP-2 (MK2) and Hsp27, besides the slight increase in the percentage of the G2/M cell cycle population $24-48 \mathrm{~h}$ after IR recovery (Supplementary Figures S2 and S7).

The most important finding of this systematic RPPA analysis is the identification of PKC as a key player that orchestrates the downstream signaling pathways regulating apoptosis and cell survival (Figure 6). IR-dependent PKC activation regulated $\mathrm{Bad}, \mathrm{Bcl}-2$ and $\mathrm{CREB}$ to prevent apoptosis and to induce prosurvival signaling. Whether PKC family members directly phosphorylate the identified downstream proteins or rather indirectly affect their activation is currently not known. Interestingly, PKCs are known to translocate to the nucleus ${ }^{35}$ and all identified regulatory components (Bad, Bcl-2, CREB) contain putative target sites for phosphorylation by PKC. ${ }^{36}$ PKC inhibitors, or PKC downregulation before IR treatment, downregulated antiapoptotic factors (Bad phosphorylation, $\mathrm{Bcl}-2$ ) and induced apoptosis (ARTD1 cleavage, increased p53 stabilization, Bad upregulation, increased sub-G1 population and decline in cell number). Sensitization of primary fibroblasts by PKC inhibitors or downregulation thus induced an apoptotic program that is mediated by effects on CREB, Bad and proapoptotic genes. PKC-dependent regulation of cell survival, apoptosis as well as cell cycle progression is thus proposed as a part of the mechanism by which primary fibroblasts resist high IR doses and circumvent apoptosis, which is in agreement with the high DNA repair efficiency and the PKC-dependent regulation of p53 function. ${ }^{16,37}$ The inhibitor and siRNA experiments described here imply PKC signaling in the prevention of apoptosis in human primary MRC-5 and IMR-90 fibroblasts. However, these analyses do not identify which PKC family member mediates the observed phenotypes. The RPPA analysis identified PKC $\delta$ activation, which was previously shown to be induced upon DNA damage ${ }^{38}$ and linked to pro- and antiapoptotic functions (Basu and $\mathrm{Pal}^{39}$ and many reference therein). Future studies on the upstream regulators relevant for PKC activation upon IR in MRC-5 and IMR-90 cells will identify the required cofactors and signaling components and thereby indicate which PKC subgroup mediates the antiapoptotic function. Taken together, our findings provide the cellular mechanism, which is responsible for this phenotype and may thus open up possiblities for new treatment schemes of highly IR-resistant tumors.

This result has not only important implications for our understanding of the IR response but also for the comprehension of nuclear regulatory events and supports the concept of the cellular, in contrast to the nuclear, radiation response. ${ }^{40}$ Cellular stress such as IR is perceived at the plasma membrane and in the cytoplasm and initiates cytoplasmic signaling pathways that consecutively control nuclear events such as DNA repair. This is also suggested by the induction of IR-induced signaling in cells exposed to IR conditioned medium, which is termed the 'bystander effect'. ${ }^{41}$ The classical DDR, comprised of nuclear events regulating cell cycle progression and DNA repair, is thus preceded and controlled by the cytoplasmic radiation response, which is mediated by the PKC signaling pathway as well as other signaling pathways such as the MEK-ERK pathway.

This RPPA network analysis of IR-induced signaling identified a new, cytoplasmic, PKC-dependent regulatory mechanism that conditions stressed cells by preventing apoptosis. The PKC-dependent induction of prosurvival signaling and evasion of apoptosis is thus a mechanism, which renders primary human fibroblasts resistant to high doses of IR, and may thereby protect the microenvironment and permit survival of tumors. Our results thus provide an explanation for the cellular response to severe irradiation stress and will therefore help optimize and improve radiotherapy. 
Materials and Methods

Cell culture, IR treatment, siRNA transfection, Iysis, viability and senescence assays. The MRC- 5 and IMR-90 human lung fibroblast cell strains ${ }^{42,43}$ were obtained from the American Type Culture Collection and cultured in supplemented MEM (Invitrogen; Life Technologies, Carlsbad, CA, USA). Cells were exposed to IR using an X-ray generator (Pantak Seifert X-ray System, Ahrensburg, Germany; $120 \mathrm{kV} ; 19 \mathrm{~mA}$; aluminum filter, $3.11 \mathrm{~Gy} / \mathrm{min})$ and recovered for different time periods. Inhibitor treatment was performed as indicated in the figure legends before the exposure to IR. To reduce PKC expression, $1 \times 10^{5} \mathrm{MRC}-5$ cells were transfected using human siPKC pan (Santa Cruz Biotechnology, Dallas, TX, USA; sc-29449) over 3 and 4 days, before irradiation. Whole cell extracts were prepared with Zeptosens Cell Lysis Buffer CLB1 (Bayer Technology Services $\mathrm{GmbH}$, Leverkusen, Germany) or RIPA lysis buffer and total protein concentration was determined using the standard Lowry method. Cell viability was determined by seeding $2 \times 10^{3}$ cells in 96-well plates overnight before irradiation or drug treatment. Cell viability was quantified using the WST-1 proliferation reagent (Roche, Basel, Switzerland) or alamarBlue cell viability assay (Invitrogen) and a plate reader (Tecan, Männedorf, Switzerland). The clonogenic and senescence assays were performed as described elsewhere. ${ }^{44,45}$

Reverse phase protein arrays. RPPA were prepared as described.$^{46}$ In brief, whole cell extracts were spotted onto hydrophobically coated Zeptosens Chips (Bayer Technology Services GmbH). Serially diluted lysates (100, 75, 50 and $25 \%$ ) were arrayed in duplicates onto hydrophobic Zeptosens Chips using the Nanoplotter NP2.0 (GeSiM; Gesellschaft für Silizium-Mikrosysteme mbH, Grosserkmannsdorf, Germany), followed by blocking in an ultrasonic nebulizer (ZeptoFOG; Bayer Technology Services $\mathrm{GmbH}$ ). Antibody incubation, microarray data acquisition (ZeptoREADER; Bayer Technology Services $\mathrm{GmbH}$ ) and data analysis (ZeptoVIEW version 3.1.0.2; Bayer Technology Services $\mathrm{GmbH}$ ) was performed exactly as described. ${ }^{47}$ The eight data points (100, 75, 50 and $25 \%$ lysate amount in duplicates) were fitted using a weighted linear least-squares fit ${ }^{48}$ and the relative fluorescence intensity determined by interpolating at the median protein concentration or modification. To correct for small variations in protein content, relative intensities were normalized to the signals of $\beta$-catenin, which did not show any significant variation (ANOVA, $P<0.05 ; 1.5 \times$ S.D.) in response to IR over indicated time points.

Significance and clustering analysis. To identify significant proteome changes in response to IR, relative fluorescence intensities were imported to $\mathrm{MeV}$ version $4.6{ }^{49}$ Relative fluorescence intensities were $\log 2$ transformed and normalized, before performing statistical analysis using one-way ANOVA as described in Zar. ${ }^{50}$ The mean transformed fluorescence intensities for group 1 (untreated: $0.5,2,4$ and $8 \mathrm{~h}$ ), group 2 (biological triplicates of 10 or 40 Gy at $0.5 \mathrm{~h}$ ), group 3 (biological triplicates of 10 or 40 Gy at $2 \mathrm{~h}$ ), group 4 (biological triplicates of 10 or 40 Gy at $4 \mathrm{~h}$ ) and group 5 (biological triplicates of 10 or $40 \mathrm{~Gy}$ at $8 \mathrm{~h}$ ) were compared using F-statistics with $P<0.05$. Owing to technical problems during preparation of the serial dilution of the whole cell extracts, two biological replicates for the $8 \mathrm{~h}$ time point of $10 \mathrm{~Gy}$ irradiated samples ( $10 \mathrm{~Gy}$ at $8 \mathrm{~h}$ ) and one biological replicate for the 2 and $8 \mathrm{~h}$ time point of 40 Gy irradiated samples ( $40 \mathrm{~Gy}$ at $2 \mathrm{~h}$ and $40 \mathrm{~Gy}$ at $8 \mathrm{~h}$ ) were excluded from the statistical analysis. For fold-change analysis, transformed means of the biological replicates were normalized to the untreated sample (set as 1) and proteome changes were filtered (cutoff set at $1.5 \times$ S.D. equal to $\log 2>0.27 /<-0.27$ for 10 Gy or $\log 2>0.29 /<-0.29$ for 40 Gy). Significant proteome changes in response to IR were selected, if significant by one-way ANOVA $(P<0.05)$ and fold cutoff $(1.5 \times$ S.D. $)$. Alternatively, significance analysis was performed using two-tailed Student's $t$-test $(P<0.05)$. Similar profiles of the fold changes over time were identified by clustering analysis using the Self Organizing Tree Algorithm ${ }^{51}$ and default parameters of $\mathrm{MeV}$ version 4.6. ${ }^{49}$

Pathway and network analysis. Gene pathway membership data were obtained from protein interaction database, $P \mathrm{PI}^{52}$ and KEGG. ${ }^{53} \mathrm{~A}$ total of 200 and 211 pathways were obtained from PID and KEGG, respectively. For statistical analysis, all analyzed proteins in this study (unique IDs) were set as the background list and all pathways consisting of more than five proteins from the background list were considered for statistical analysis by Fisher's exact test, resulting in a total of 93 pathways from PID and 63 from KEGG. Fisher's exact test was performed to identify pathways significantly affected by proteins (modifications) altered in response to irradiation (significant by ANOVA and fold change) using the $\mathrm{R}$ statistical framework. ${ }^{54}$ To account for multiple testing, $P$-values were corrected for false discovery rates (FDRs) using Benjamini-Hochberg correction.
We have used an FDR-corrected $P$-value cutoff of 0.1 to identify pathways significantly affected by proteome changes.

Significant proteome changes, identified by statistical (ANOVA) and fold-change analysis (log 2 cutoff) were subjected to protein-protein interaction analysis using STRING (v. 9.0, http://www.string-db.org/). ${ }^{55}$ Only interactions with a STRING score of 0.7 and above were further analyzed using Cytoscape (http://www.cytoscape.org/) ${ }^{56}$

Immunoblotting. For western blot analysis, proteins were separated by SDSPAGE gel electrophoresis and bands were visualized by using either horseradish peroxidase-conjugated antibodies (1:5000; GE Healthcare, Life Sciences, Uppsala, Sweden) and ECL detection (GE Healthcare) or IR-dye-conjugated antibodies (1: 15 000; LI-COR Biosciences) and detection by the Odyssey infrared imaging system (LI-COR Biosciences, Lincoln, NE, USA). For quantification, bands were analyzed by ImageJ 1.46 (ref. 57) and the Odyssey imaging software (LI-COR Biosciences).

Antibodies used for western blotting were anti-ATM (GeneTex, Irvine, CA, USA), anti-ATM Phospho (pS1981) (Epitomics-an Abcam Company, Burlingame, CA, USA), anti-Bad (CST), anti-Bad Phospho (pS136) (Cell Signaling Technology (CST), Danvers, MA, USA), anti-Chk1 (CST), anti-Chk1 Phospho (pS345) (1:500; CST), anti-Chk2 Phospho (pT68) (CST), anti-CREB (CST), anti-CREB Phospho (pS133)/anti-ATF-1 (phospho) (CST), anti-histone H2A.X Phospho (pS139) (Millipore, Billerica, MA, USA), anti-Hsp27 (CST), anti-Hsp27 Phospho (pS78) (1:500; CST), anti-PARP1 (Santa Cruz Biotechnology), anti-PARP1 cleaved (1:500; CST), anti-p16 (1:500; Santa Cruz Biotechnology), anti-p21 (Santa Cruz Biotechnology), anti-p38 (CST), anti-p38 Phospho (pThr180/Tyr182), anti-p44/42 Erk1/2 (CST), anti-p44/42 Erk1/2 Phospho (pThr202/Tyr204) (CST), anti-p53 (Santa Cruz Biotechnology), anti-Rb (1:500; Epitomics), anti-Rb (pS780) (CST), anti-tubulin (1:10 000; Sigma-Aldrich, St Louis, MO, USA), anti-PKC $\beta \|$ Phospho (pT641) (CST), anti-PKC $\delta$ (CST), anti-PKC $\zeta / \lambda$ (CST) and anti-PKC $\zeta / \lambda$ Phospho (pT410/pT403) (CST). Unless otherwise stated, antibody dilution was 1:1000.

Immunofluorescence microscopy. MRC-5 cells grown on cover slips over night $\left(\approx 1 \times 10^{4}\right.$ cells) were irradiated and immunohistochemically stained with primary (1:500 mouse anti-histone H2A.X Phospho (S139) immunoglobulin G1 (IgG1) (Millipore) or 1:500 rabbit anti-53BP1 IgG1 (Santa Cruz Biotechnology)) and secondary antibodies (1:250 FITC- or cyanine 3-conjugated IgG antimouse IgG (Jackson ImmunoResearch Laboratories, West Grove, PA, USA) or 1:250 Alexa Fluor 488-conjugated anti-rabbit lgG (Invitrogen)).

Flow cytometry. Cell cycle analysis of IR-treated or -untreated MRC- 5 cells was performed using standard ethanol fixation/PI-staining protocol and flow cytometry analysis (FACS) with a Dako CyAn ADP flow cytometer (Dako, North America, Carpinteria, CA, USA). For sub-G1 peak analysis of IMR-90, cell debris and necrotic cells were gated out according to the protocol of Riccardi and Nicoletti. ${ }^{58}$ Annexin $V$ staining was performed using the FITC Annexin V apoptosis detection kit (BD Biosciences, San Jose, CA, USA) and a Dako CyAn ADP flow cytometer (Dako).

RNA extraction and real-time PCR analysis. Total RNA was reverse transcribed using High-Capacity cDNA Reverse Transcription kit (Applied Biosystems; Life Technologies). Real-time PCR was performed using SYBR green premixed buffer and analyzed by the Rotor-Gene Q cycler (Qiagen, Hilden, Germany).

\section{Conflict of Interest}

JT was Zeptosens Technology Manager at Bayer Technology Services $\mathrm{GmbH}$ and is currently Group Head for Process Analytical Technologies at the same company. JvO was Head of Business Development at Zeptosens, a division of Bayer (Schweiz) AG. All the other authors declare no conflict of interest.

Acknowledgements. F Freimoser (University of Zurich) provided editorial assistance and critical input during the writing. We thank M Ehrat, G Balciunaite and $J$ Grognux for technical assistance with protein arrays. This work was supported in part by the Kanton of Zurich (to MOH), Oncosuisse (KLS 02396-02-2009) and the UBS foundation. 


\section{Author contributions}

$\mathrm{AB}, \mathrm{NK}, \mathrm{JT}$ and $\mathrm{MOH}$ designed the experiments; $\mathrm{AB}, \mathrm{NK}$ and $\mathrm{KM}$ performed and analyzed the experiments; and JvO, $\mathrm{HR}, \mathrm{MB}$ and $\mathrm{MOH}$ supervised the study. All authors contributed to the preparation of the manuscript.

1. Harper JW, Elledge SJ. The DNA damage response: ten years after. Mol Cell 2007; 28: 739-745.

2. Shiloh Y. ATM and related protein kinases: safeguarding genome integrity. Nate Rev Cancer 2003; 3: 155-168.

3. Bonner WM, Redon CE, Dickey JS, Nakamura AJ, Sedelnikova OA, Solier $\mathrm{S}$ et al. GammaH2AX and cancer. Nat Rev Cancer 2008; 8: 957-967.

4. Surova O, Zhivotovsky B. Various modes of cell death induced by DNA damage. Oncogene 2012; E-pub ahead of print; doi: 10.1038/onc.2012.556.

5. Roos WP, Kaina B. DNA damage-induced cell death by apoptosis. Trends Mol Med 2006; 12: $440-450$.

6. Sabin RJ, Anderson RM. Cellular senescence - its role in cancer and the response to ionizing radiation. Genome Integr 2011; $2: 7$.

7. Bennetzen M, Larsen D, Bunkenborg J, Bartek J, Lukas J, Andersen J. Site-specific phosphorylation dynamics of the nuclear proteome during the DNA damage response. $\mathrm{Mol}$ Cell Proteomics 2010; 9: 1314-1323.

8. Bensimon A, Schmidt A, Ziv Y, Elkon R, Wang SY, Chen DJ et al. ATM-dependent and independent dynamics of the nuclear phosphoproteome after DNA damage. Sci Signal 2010; 3: rs3.

9. Beli P, Lukashchuk N, Wagner SA, Weinert BT, Olsen JV, Baskcomb L et al. Proteomic investigations reveal a role for RNA processing factor THRAP3 in the dna damage response. Mol Cell 2012; 46: 212-225.

10. Lee MJ, Ye AS, Gardino AK, Heijink AM, Sorger PK, MacBeath G et al. Sequential application of anticancer drugs enhances cell death by rewiring apoptotic signaling networks. Cell 2012; 149: 780-794.

11. Tentner AR, Lee MJ, Ostheimer GJ, Samson LD, Lauffenburger DA, Yaffe MB. Combined experimental and computational analysis of DNA damage signaling reveals context-dependent roles for Erk in apoptosis and G1/S arrest after genotoxic stress. Mol Syst Biol 2012; 8: 568.

12. van Oostrum J, Voshol $\mathrm{H}$. Antibody-based proteomics to study cellular signalling networks. Eur Pharmaceut Rev 2008; 2: 31-35.

13. Paweletz CP, Charboneau L, Bichsel VE, Simone NL, Chen T, Gillespie JW et al. Reverse phase protein microarrays which capture disease progression show activation of prosurvival pathways at the cancer invasion front. Oncogene 2001; 20: 1981-1989.

14. Nishizuka S, Ramalingam S, Spurrier B, Washburn FL, Krishna R, Honkanen P et al. Quantitative protein network monitoring in response to DNA damage. J Proteome Res 2008; 7: 803-808.

15. Hudson ME, Pozdnyakova I, Haines K, Mor G, Snyder M. Identification of differentially expressed proteins in ovarian cancer using high-density protein microarrays. Proc Natl Acad Sci USA 2007; 104: 17494-17499.

16. Kuhne M, Riballo E, Rief N, Rothkamm K, Jeggo PA, Lobrich M. A double-strand break repair defect in ATM-deficient cells contributes to radiosensitivity. Cancer Res 2004; 64: 500-508.

17. Lobrich M, Shibata A, Beucher A, Fisher A, Ensminger M, Goodarzi AA et al. gammaH2AX foci analysis for monitoring DNA double-strand break repair: strengths, limitations and optimization. Cell Cycle 2010; 9: 662-669.

18. Yoshida K. Role for PKC $\delta$ on apoptosis in the DNA damage response. In: Chen CC (eds). Selected Tpics in DNA Repair. InTech: San Diego, USA, 2011. pp 293-304.

19. Newton AC. Protein kinase C: poised to signal. Am J Physiol Endocrinol Metab 2010; 298 : E395-E402.

20. Jackson DN, Foster DA. The enigmatic protein kinase Cdelta: complex roles in cell proliferation and survival. FASEB J 2004; 18: 627-636.

21. Kosar M, Bartkova J, Hubackova S, Hodny Z, Lukas J, Bartek J. Senescence-associated heterochromatin foci are dispensable for cellular senescence, occur in a cell type- and insultdependent manner and follow expression of p16(ink4a). Cell Cycle 2011; 10: 457-468.

22. Cosentino C, Grieco D, Costanzo V. ATM activates the pentose phosphate pathway promoting anti-oxidant defence and DNA repair. EMBO J 2011; 30: 546-555.

23. Meek DW. Tumour suppression by p53: a role for the DNA damage response? Nat Rev Cancer 2009; 9: 714-723.

24. Lavin MF, Gueven N. The complexity of p53 stabilization and activation. Cell Death Differ 2006; 13: 941-950.

25. Parekh DB, Ziegler W, Parker PJ. Multiple pathways control protein kinase C phosphorylation. EMBO J 2000; 19: 496-503.

26. Lonze BE, Riccio A, Cohen S, Ginty DD. Apoptosis, axonal growth defects, and degeneration of peripheral neurons in mice lacking CREB. Neuron 2002; 34: 371-385.

27. Datta SR, Dudek H, Tao X, Masters S, Fu H, Gotoh Y et al. Akt phosphorylation of BAD couples survival signals to the cell-intrinsic death machinery. Cell 1997; 91: 231-241.

28. Adams JM, Cory S. The Bcl-2 apoptotic switch in cancer development and therapy. Oncogene 2007; 26: 1324-1337.

29. Vogler M, Dinsdale D, Dyer MJ, Cohen GM. Bcl-2 inhibitors: small molecules with a big impact on cancer therapy. Cell Death Differ 2009; 16: 360-367.

30. Lawless C, Wang C, Jurk D, Merz A, Zglinicki T, Passos JF. Quantitative assessment of markers for cell senescence. Exp Gerontol 2010; 45: 772-778.

31. Torudd J, Protopopova M, Sarimov R, Nygren J, Eriksson S, Markova E et al. Doseresponse for radiation-induced apoptosis, residual 53BP1 foci and DNA-loop relaxation in human lymphocytes. Int J Radiat Biol 2005; 81: 125-138.

32. Meyn RE, Munshi A, Haymach JV, Milas L, Ang KK. Receptor signaling as a regulatory mechanism of DNA repair. Radiother Oncol 2009; 92: 316-322.

33. Bulavin DV, Higashimoto Y, Popoff IJ, Gaarde WA, Basrur V, Potapova $O$ et al. Initiation of a G2/M checkpoint after ultraviolet radiation requires p38 kinase. Nature 2001; 411: 102-107.

34. Manke IA, Nguyen A, Lim D, Stewart MQ, Elia AE, Yaffe MB. MAPKAP kinase-2 is a cell cycle checkpoint kinase that regulates the $\mathrm{G} 2 / \mathrm{M}$ transition and $S$ phase progression in response to UV irradiation. Mol Cell 2005; 17: 37-48.

35. Martelli AM, Evangelisti C, Nyakern M, Manzoli FA. Nuclear protein kinase C. Biochim Biophys Acta 2006; 1761: 542-551.

36. Xue Y, Ren J, Gao X, Jin C, Wen L, Yao X. GPS 2.0, a tool to predict kinase-specific phosphorylation sites in hierarchy. Mol Cell Proteomics 2008; 7: 1598-1608.

37. Yoshida K. Protein kinase C, p53, and DNA damage. In: Kazanietz MG (eds). Protein Kinase $C$ in Cancer Signaling and Therapy. Springer: Berlin, 2010. pp 253-265.

38. Yoshida K, Miki Y, Kufe D. Activation of SAPK/JNK signaling by protein kinase Cdelta in response to DNA damage. J Biol Chem 2002; 277: 48372-48378.

39. Basu A, Pal D. Two faces of protein kinase Cdelta: the contrasting roles of PKCdelta in cell survival and cell death. Scientific World J 2010; 10: 2272-2284.

40. Schmidt-Ullrich RK, Dent P, Grant S, Mikkelsen RB, Valerie K. Signal transduction and cellular radiation responses. Radiat Res 2000; 153: 245-257.

41. Baskar R, Balajee AS, Geard CR, Hande MP. Isoform-specific activation of protein kinase $\mathrm{c}$ in irradiated human fibroblasts and their bystander cells. Int J Biochem Cell Biol 2008; 40: 125-134.

42. Jacobs JP, Jones CM, Baille JP. Characteristics of a human diploid cell designated MRC-5. Nature 1970; 227: 168-170.

43. Nichols WW, Murphy DG, Cristofalo VJ, Toji LH, Greene AE, Dwight SA. Characterization of a new human diploid cell strain, IMR-90. Science 1977; 196: 60-63.

44. Franken NA, Rodermond HM, Stap J, Haveman J, van Bree C. Clonogenic assay of cells in vitro. Nat Protoc 2006; 1: 2315-2319.

45. Dimri GP, Lee X, Basile G, Acosta M, Scott G, Roskelley C et al. A biomarker that identifies senescent human cells in culture and in aging skin in vivo. Proc Natl Acad Sci USA 1995; 92: 9363-9367.

46. Pawlak M, Schick E, Bopp MA, Schneider MJ, Oroszlan P, Ehrat M. Zeptosens' protein microarrays: a novel high performance microarray platform for low abundance protein analysis. Proteomics 2002; 2: 383-393.

47. Voshol H, Ehrat M, Traenkle J, Bertrand E, van Oostrum J. Antibody-based proteomics: analysis of signaling networks using reverse protein arrays. FEBS J 2009; 276: 6871-6879.

48. Bevington PR. Data Reduction and Error Analysis for the Physical Sciences. 3rd edn McGraw-Hill: New York, NY, 2002. p 352.

49. Saeed Al, Sharov V, White J, Li J, Liang W, Bhagabati N et al. TM4: a free, open-source system for microarray data management and analysis. Biotechniques 2003; 34: 374-378.

50. Zar JH. Biostatistical Analysis. 5th edn Prentice-Hall: Upper Saddle River, NJ, 2009. p 960.

51. Herrero-Yraola A, Bakhit SM, Franke P, Weise C, Schweiger M, Jorcke D et al. Regulation of glutamate dehydrogenase by reversible ADP-ribosylation in mitochondria. EMBO J 2001; 20: 2404-2412.

52. Schaefer CF, Anthony K, Krupa S, Buchoff J, Day M, Hannay T et al. PID: the Pathway Interaction Database. Nucleic Acids Res 2009; 37: D674-D679.

53. Kanehisa M, Goto S, Furumichi M, Tanabe M, Hirakawa M. KEGG for representation and analysis of molecular networks involving diseases and drugs. Nucleic Acids Res 2010; 38: D355-D360.

54. Ihaka R, Genleman RR. A language for data analysis and graphics. J Comput Graph Stat 1996; 5: 299-314.

55. Szklarczyk D, Franceschini A, Kuhn M, Simonovic M, Roth A, Minguez $P$ et al. The STRING database in 2011: functional interaction networks of proteins, globally integrated and scored. Nucleic Acids Res 2011; 39: D561-D568.

56. Shannon P, Markiel A, Ozier O, Baliga NS, Wang JT, Ramage D et al. Cytoscape: a software environment for integrated models of biomolecular interaction networks. Genome Res 2003; 13: 2498-2504.

57. Schneider CA, Rasband WS, Eliceiri KW. NIH Image to ImageJ: 25 years of image analysis. Nat Methods 2012; 9: 671-675.

58. Riccardi C, Nicoletti I. Analysis of apoptosis by propidium iodide staining and flow cytometry. Nat Protoc 2006; 1: 1458-1461.

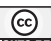

SOMERIAHIS

published by Nature Publishing Group. This work is licensed under the Creative Commons Attribution-NonCommercial-No Derivative Works 3.0 Unported License. To view a copy of this license, visit http://creativecommons.org/licenses/by-nc-nd/3.0/ 